\title{
GOMS and CCT Based User Interface For Education Game Activities
}

\author{
Umi Rosyidah $^{1}$, Hanny Haryanto ${ }^{2}$, Acun Kardianawati ${ }^{3}$ \\ ${ }^{1}$ Informatics Engineering Department, Faculty of Computer Science, Universitas Dian Nuswantoro \\ Jln. Imam Bonjol No.205-207, Semarang 50131, Indonesia, e-mail: umi.rosyidah@dsn.dinus.ac.id \\ ${ }^{2}$ Informatics Engineering Department, Faculty of Computer Science, Universitas Dian Nuswantoro \\ JIn. Imam Bonjol No.205-207, Semarang 50131, Indonesia, e-mail: \\ hanny.haryanto@dsn.dinus.ac.id \\ ${ }^{3}$ Information System Department, Faculty of Computer Science, Universitas Dian Nuswantoro \\ JIn. Imam Bonjol No.205-207, Semarang 50131, Indonesia, e-mail: \\ acun.kardianawati@dsn.dinus.ac.id
}

\section{ARTICLE INFO}

Article history:

Received 23 July 2018

Received in revised form 30 July 2018

Accepted 3 Agustus 2018

Available online 17 Agustus 2018

\begin{abstract}
Aktivitas pada game edukasi mempunyai peran yang sangat penting supaya pemain dapat memahami materi pembelajaran yang diberikan dalam game. Aktivitas ini membentuk pengalaman sehingga pengguna dapat menerapkan materi yang diajarkan. User interface merupakan elemen penting pada game untuk menyajikan aktivitas tersebut. Perancangan user interface pada game edukasi seringkali tidak terstruktur dan terkonsep dengan baik sehingga aktivitas pembelajaran yang disajikan tidak dirancang dengan baik. Penelitian ini menggunakan model GOMS dan CCT untuk merancang user interface yang nantinya akan menghasilkan aktivitas pembelajaran dalam game edukasi. GOMS dan CCT adalah model kognitif dalam kategori representasi hirarki tugas dan tujuan pengguna yang terdiri dari satu tujuan tingkat tinggi yang kemudian didekomposisikan menjadi deretan unit tugas dan dapat didekomposisikan lagi sampai pada level operator dasar. Aktivitas dalam game edukasi dalam penelitian ini dirancang berdasarkan model Appreciative Learning. Penelitian ini menghasilkan desain user interface berbasis GOMS dan CCT dalam menunjang aktivitas pembelajaran dalam game edukasi.
\end{abstract}

Keywords: game edukasi, GOMS, CCT, user interface, aktivitas pembelajaran.

\section{Pendahuluan}

Game dipandang sebagai media digital yang efektif untuk memberikan pengalaman praktis pembelajaran, sikap positif dan kesenangan dalam belajar [1]. Dalam proses pembelajaran banyak media yang dapat digunakan, salah satunya adalah game. Game dilihat sebagai media digital efektif untuk memberikan pengalaman praktis dalam pembelajaran, memberikan sikap positif dan kesenangan dalam proses belajar [2]. Dengan pengalaman yang diperoleh ini aktivitas yang dikerjakan akan lebih mendalam sehingga pengguna bisa lebih memahami isi materi pembelajaran. Pengalaman pengguna didefinisikan sebagai respon atau persepsi pengguna dalam menggunakan suatu sistem atau perangkat lunak [2]. Game adalah sesuatu yang memiliki akhir (tujuan dan hasil) dan cara mencapainya (peraturan) [3]. 
Antarmuka game yang merupakan elemen game yang berhubungan dengan interaksi antara pembelajar dan game merupakan salah satu elemen yang paling penting dalam game edukasi. Dengan menggunakan elemen antarmuka ini, game dapat mengarahkan aktivitas yang dilakukan oleh pembelajar dan membentuk pengalaman gameplay yang unik [4]. Antarmuka merupakan gabungan dari elemen-elemen suatu sistem, elemen-elemen dari pengguna, dan juga komunikasi atau interaksi di antara keduanya. Pengguna hanya dapat menggunakan produk melalui antarmuka pengguna [5]. Peran antarmuka sangat penting dalam kedayagunaan. Oleh karena itu perancangan antarmuka pengguna perlu dilihat sebagai salah satu proses utama dalam keseluruhan pembangunan suatu sistem. Rekayasa antarmuka pengguna merupakan suatu proses yang kompleks yang memerlukan daya kreativitas tinggi, pengalaman, analisis yang terperinci dan pemahaman terhadap kebutuhan pengguna.

Model pengguna merupakan suatu model konseptual dari sebuah rancangan sistem yang diinginkan oleh pengguna dalam memanipulasi proses dan informasi yang diaplikasikan dalam sistem tersebut. Model Kognitif merupakan suatu model yang berhubungan dengan sistem interaktif yang memodelkan aspek pengguna, seperti pemahaman, pengetahuan, tujuan dan pemrosesan. Dalam penelitian ini, peneliti menggunakan model kognitif GOMS dan CCT [5]. Model GOMS umumnya terdiri dari satu tujuan tingkat tinggi yang didekomposisikan menjadi deretan unit tugas (task) yang selanjutnya dapat didekomposisikan lagi sampai pada level operator dasar. Dekomposisi tujuan antara tugas keseluruhan dan tugas unit melibatkan pemahaman terhadap strategi pemecahan masalah oleh user dan domain aplikasi secara detail. Model CCT merupakan perluasan dari GOMS. CCT mengandung banyak prediksi atau yang juga sering disebut dengan kemungkinan.

\section{Metode Penelitian}

Dalam penelitian ini model pengembangan game yang diterapkan adalah prototype dengan model aktivitas didalamnya menggunakan appreciative learning. Prototype digunakan karena peneliti lebih bisa berkomunikasi dengan pengguna dalam proses pembuatan game yang sering terjadi perubahan, sehingga pengguna memiliki gambaran dasar mengenai game yang sedang dibangun dan proses pembangunannya bisa berjalan dengan lebih cepat. Appreciative learning merupakan Model yang menunjukan tahapan-tahapan berorientasi pada aktivitas Discovery, Dream, Design dan Destiny [6]. Aktivitas yang terjadi pada bagian pertama disebut dengan tahap discovery. Tahapan ini merupakan bagian dimana pengguna bisa menemukan sesuatu yang positif atau menemukan kelebihan dalam dirinya (pengguna), hal positif tersebut misalnya pengguna bisa berkomunikasi dengan pihak lain sehingga dapat menambah kemampuan pengguna untuk berkomunikasi. Dengan berkomunikasi pengguna akan memiliki banyak teman. Tahap yang kedua adalah dream, tahapan ini melihat hal yang positif di masa depan. Pengguna bisa berfikir lebih ke depan mengenai visi dengan lebih baik. Kemudian tahapan ketiga adalah design, pada tahapan ini pengguna dapat merancang sesuatu hal yang akan berjalan dengan baik dan positif di masa depan. Dan Tahapan terakhir adalah destiny, pada tahapan ini pengguna dapat mengimplementasikan tahap Design yang sudah dirumuskan pada tahapan sebelumnya. Model aktivitas ini dapat dilihat pada Gambar 1. 


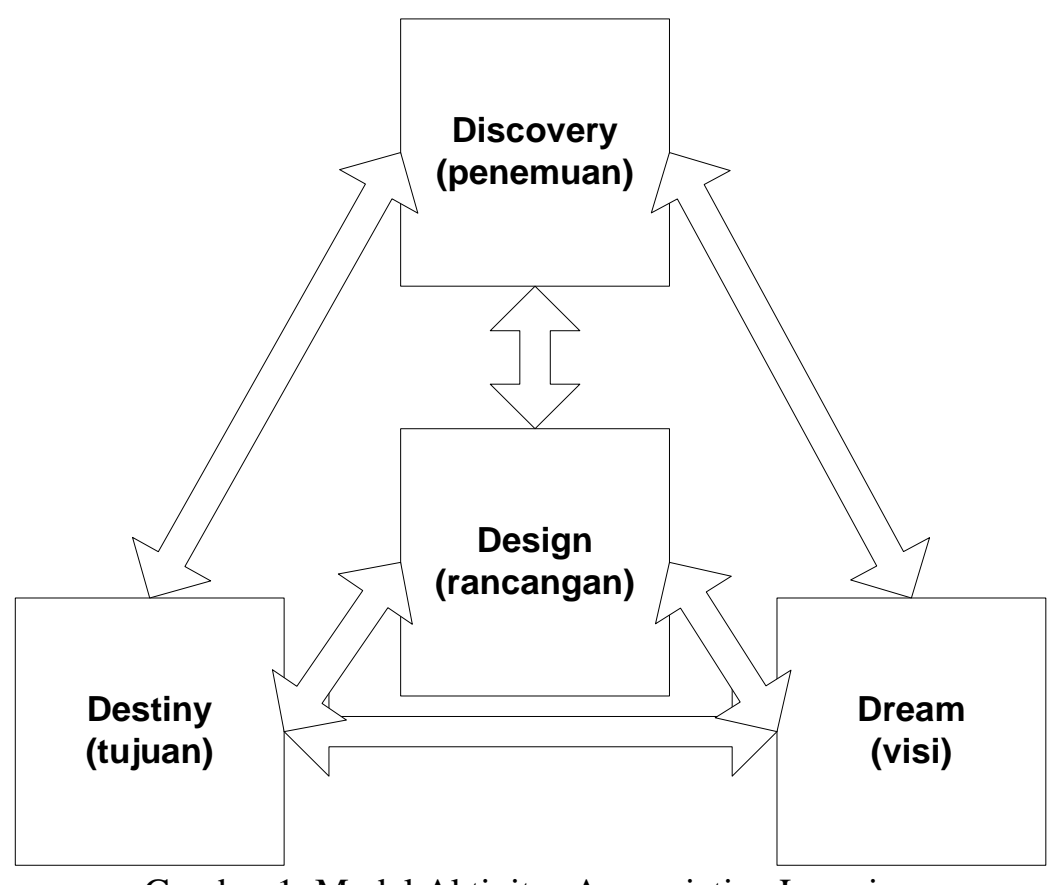

Gambar 1. Model Aktivitas Appreciative Learning

Dalam Model Aktivitas diatas diterapkan model kognitif untuk mengetahui bagaimana pengguna berinteraksi dalam tiap tahapan model aktivitas appreciative learning. Model kognitif yang diterpakan adalah GOMS dan CCT. Dari tiap tahapan aktivitas tersebut di atas dapat diuraikan sebagai berikut; Pada tahapn pertama, yaitu pada Aktivitas Discovery, pada tahap ini pengguna memiliki tujuan untuk mendapatkan reward berupa atribut komunikasi, atribut ini yang akan digunakan pada tahap berikutnya yaitu tahap Dream, dimana hasil reward ini dapat digunakan untuk menyelesaikan tujuan pada tahap Dream. Pada tahapan kedua yaitu pada aktivitas dream, pengguna memiliki tujuan untuk menentukan jenis produk yang akan dijual, pengguna harus tahu jenis produk apa yang paling disukai masyarakat, material apa saja yang dibutuhkan, pengguna juga harus memiliki ketekunan dan kebijaksanaan. Tahap aktivitas selanjutnya, yaitu aktivitas Design, dalam tahapan ini pengguna memiliki tujuan untuk mencari material untuk dapat mewujudkan pembuatan produk sesuai tujuan pada tahap sebelumnya. Pada tahap terakhir yaitu tahap Destiny, pengguna memiliki tujuan untuk menjual produk yang sudah dibuat pada tahap sebelumnya. Pada tahapan ini pengguna juga memiliki tujuan untuk memperoleh reputasi yang baik dari hasil produk yang dia jual. Jika reputasinya baik maka akan mendapat teman begitu juga sebaliknya. Semakin banyak teman maka semakin baik reputasinya. Teman ini yang nantinya juga bisa membantu si pengguna dalam proses penjualan produk.

\section{Hasil dan Analisa}

\subsection{Model GOMS dan CCT}

Dalam model GOMS pengguna harus tahu tujuan apa yang ingin dia capai, dengan tujuan yang jelas, pengguna dapat menentukan langkah-langkah apa saja yang dapat dia lakukan. Langkah-langkah yang dilakukan dalam setiap tahap bisa berbeda antara pengguna. Misalnya pada tahap aktivitas Discovery. Tahapan ini pengguna bisa memilih menggunakan mouse atau tombol pada keyboard dengan tujuan yang ingin dicapai sama. Berikut adalah contoh model GOMS pada tahap Decovery dengan tujuan untuk mendapatkan atribut komunikasi, yang nantinya setelah terkumpul atribut-atribut tersebut pengguna akan mendapatkan kunci untuk memasuki tahapan berikutnya yaitu tahapan Dream.

TRANSFORMATIKA Vol. 16, No. 1, Juli 2018: $22-30$ 
GOAL MENDAPATKAN REGULAR NICHE

Goal : mendapat atribut komunikasi (CA1, CA2,CA3)

[ Select

Tekan tombol panah arahkan pada karakter

Tekan tombol Enter untuk berkomunikasi

Tekan tombol enter saat selesai berkomunikasi (dapat atribut CA+1)

Tekan tombol panah arahkan pada karakter

Tekan tombol Enter untuk berkomunikasi

Tekan tombol enter saat selesai berkomunikasi (dapat regular niche)

Arahkan mouse pada karakter

Tekan tombol kiri untuk berkomunikasi

Tekan tombol kiri mouse untuk selesai komunikasi (dapat atribut $\mathrm{CA}+1$ )

Arahkan mouse pada karakter terakhir

Tekan tombol kiri untuk berkomunikasi

Tekan tombol kiri mouse untuk selesai komunikasi (dapat regular niche) ]

Gambar 2. Model GOMS dalam aktivitas Discovery

Setiap tahapan dalam masing-masing aktivitas, pengguna bisa memilih apa yang akan dia kerjakan, karena yang dikerjakan pada tahap sebelumnya akan berpengaruh pada tahap berikutnya. Pada tahap aktivitas Discovery pengguna mendapatkan reward regular niche, maka pada tahap berikutnya reward tersebut yang akan dia gunakan.

Tahap berikutnya adalah pada aktivitas Dream. Dalam aktivitas ini Model GOMS yang diterapkan adalah sebagai berikut:

\section{GOAL : MENDAPATKAN JENIS PRODUK YANG AKAN DIJUAL}

SubGoals : - Mendapatkan resep produk (recipe)

- Mendapatkan kemampuan (Skill)

- Mendapatkan atribut kebijaksanaan(WA)

- Mendapatkan atribut ketekunan(PA)

- Mendapatkan atribut kebermanfaatan(HA)

[ Select

Tekan tombol panah arahkan pada karakter

Tekan tombol enter ( key mainquest completed)

Tekan tombol enter (key product recipe)

Tekan tombol panah kanan arahkan pada karakter

Tekan tombol enter (got skillquest)

Tekan tombol enter (completed skillquest)

Tekan tombol enter (WA+1)

Tekan tombol enter (got skill)

Tekan tombol enter (got recipe)

Tekan tombol enter

Pilih I have time untuk mendapatkan pet

Tekan tombol panah kanan

Tekan tombol enter $(\mathrm{HA}+1)$

Arahkan tetikus pada karakter

Tekan tombol kiri untuk mendapatkan reward ]

Gambar 3. Model GOMS pada aktivitas Dream 
Selain Model GOMS, CCT juga diterapkan dalam Game ini. Model CCT menunjukan aturan-aturan produksi dalam aktivitas masing-masing. Berikut adalah contoh model CCT dalam tahap aktivitas Design dan aktivitas Destiny.

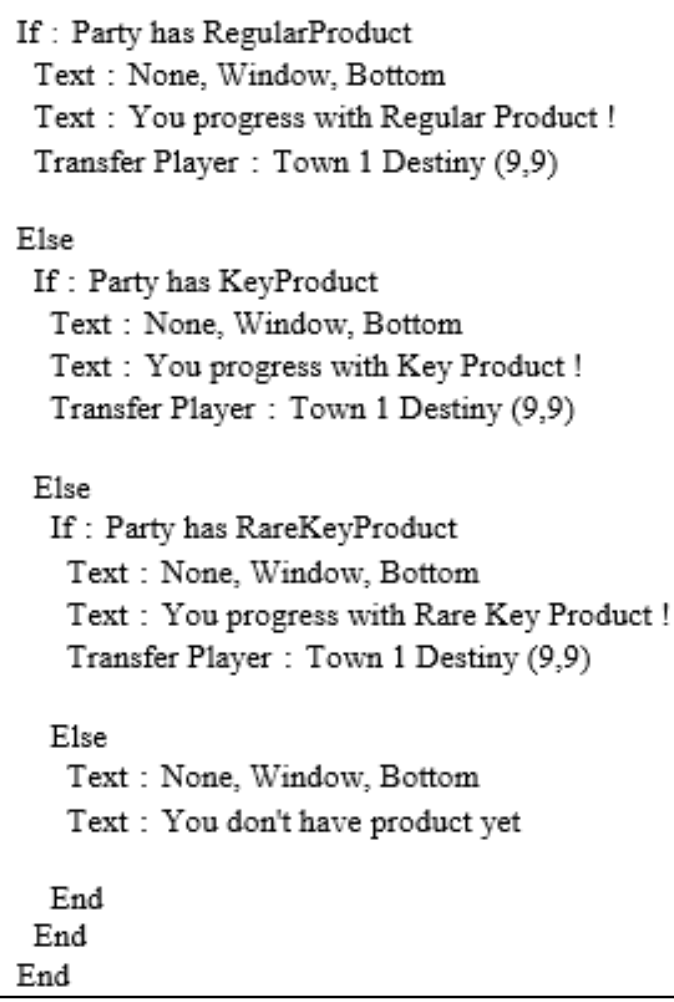

Gambar 4. Model CCT pada aktivitas Design

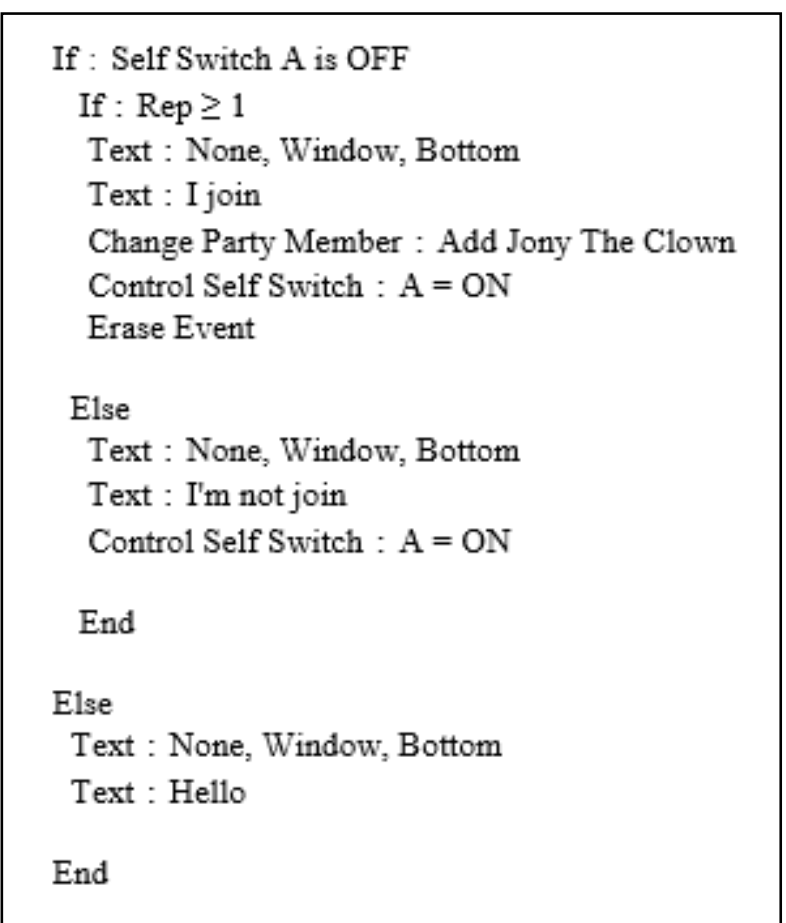

Gambar 5. Model CCT pada aktivitas Destiny 


\subsection{Game}

Game yang dibangun adalah game RPG dengan materi pembelajaran yang dimasukan adalah kewirausahaan. Pengguna diharapkan pada akhir game dapat menjual produk dan memiliki banyak teman atau relasi. Berikut adalah antarmuka game edukasi yang telah dirancang.

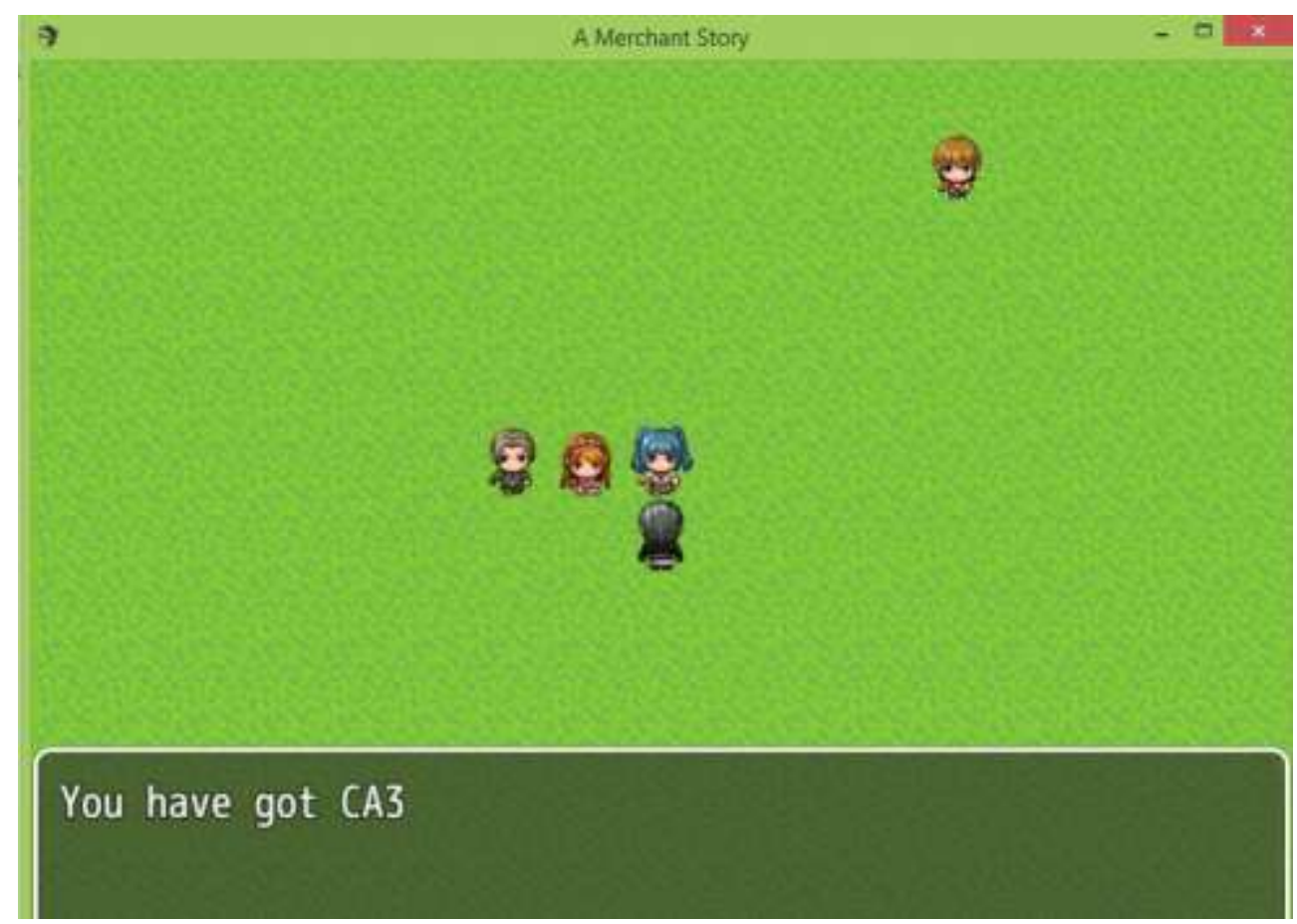

Gambar 6. Antarmuka Pengguna pada aktivitas Discovery

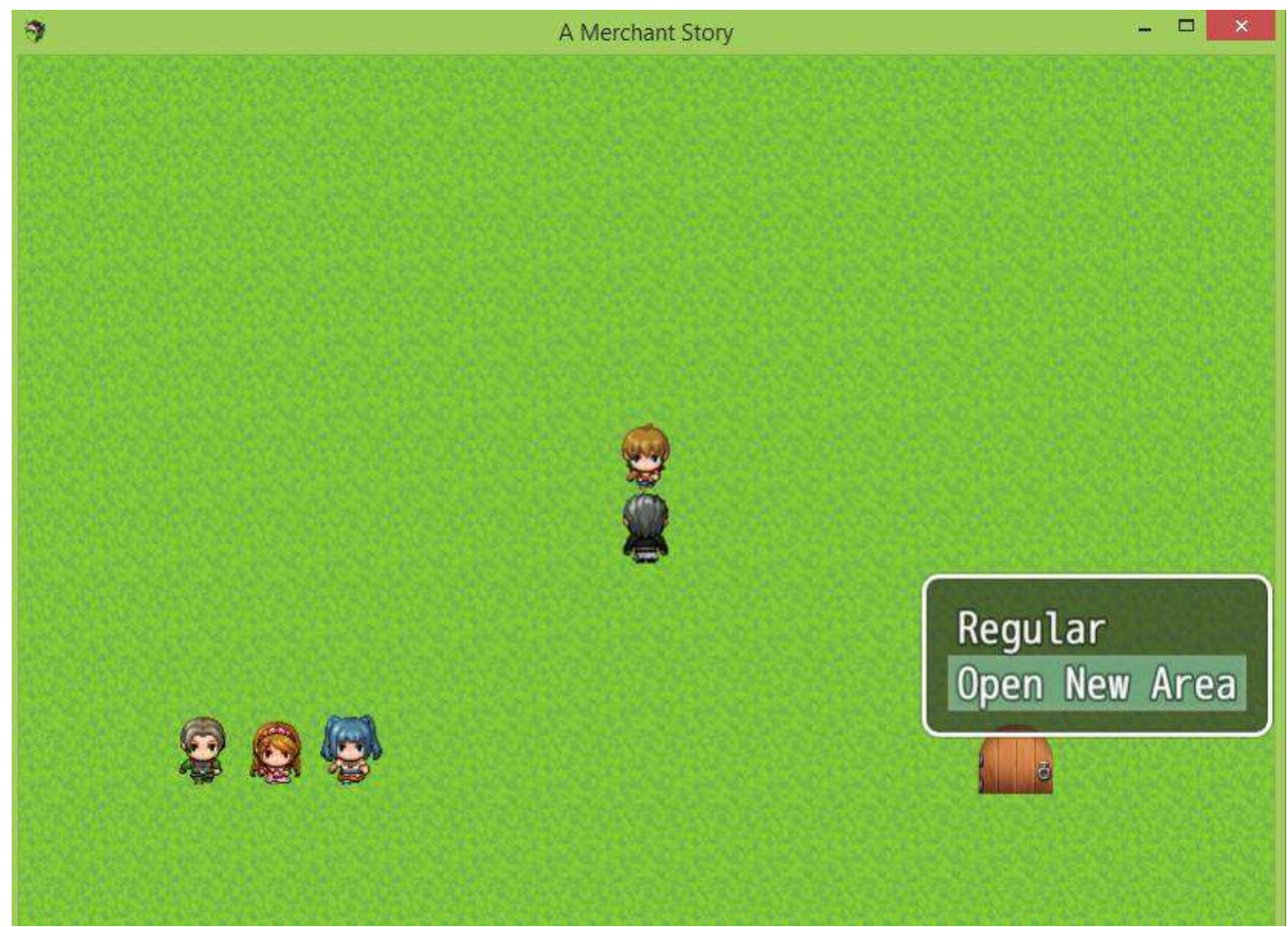

Gambar 7. Antarmuka pengguna saat akan memasuki tahap aktivitas Discovery 


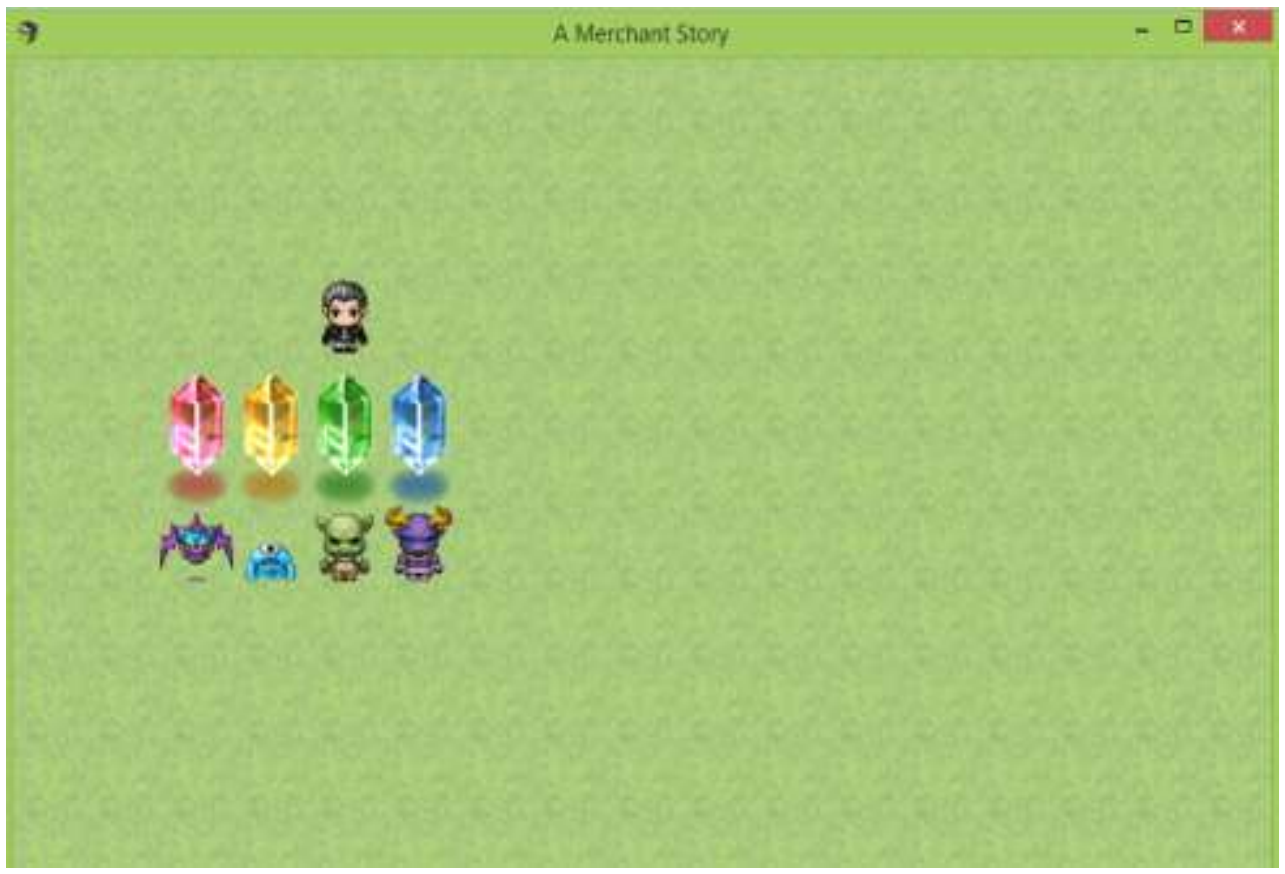

Gambar 8. Antarmuka saat pencarian item

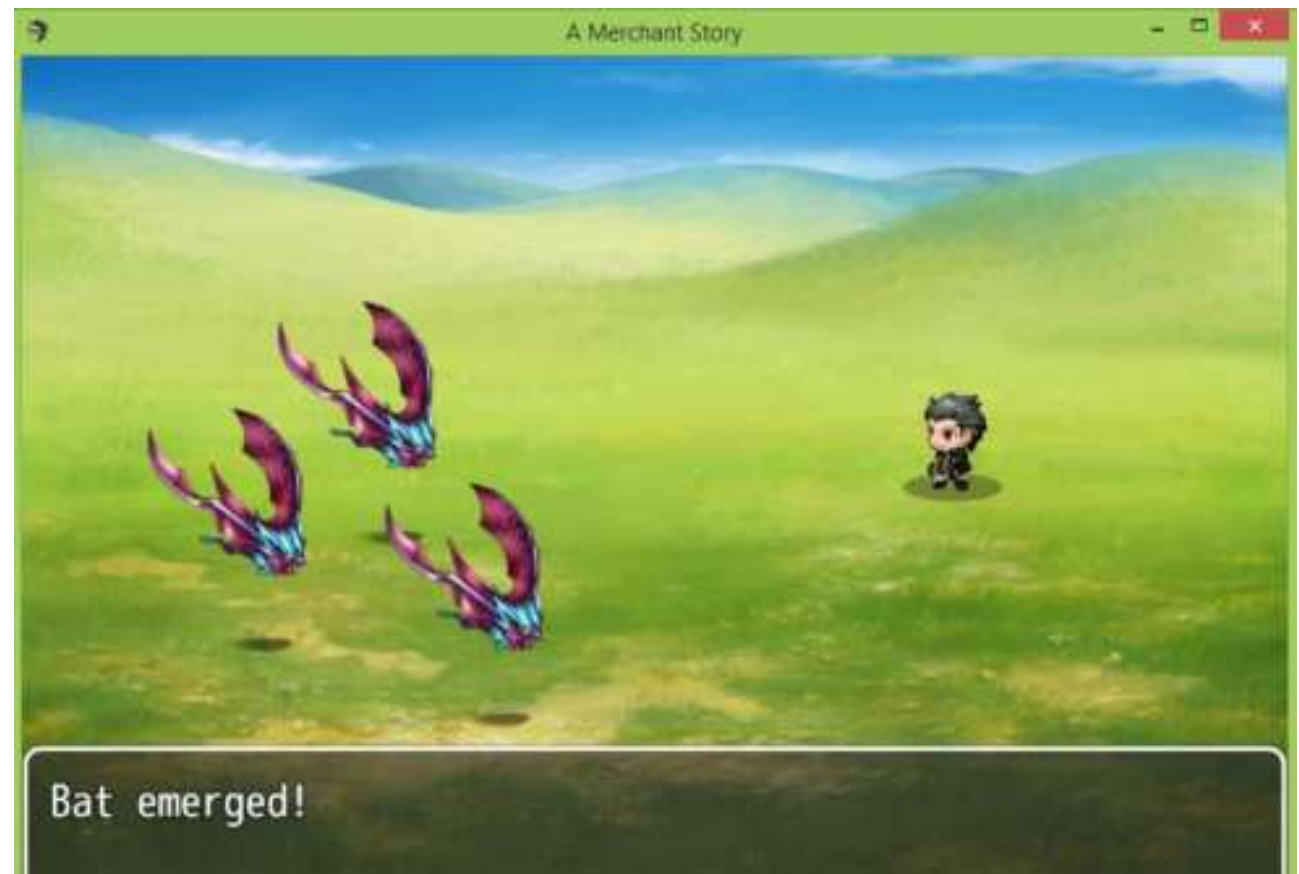

Gambar 9. Antarmuka saat pencarian item bertemu dengan musuh 


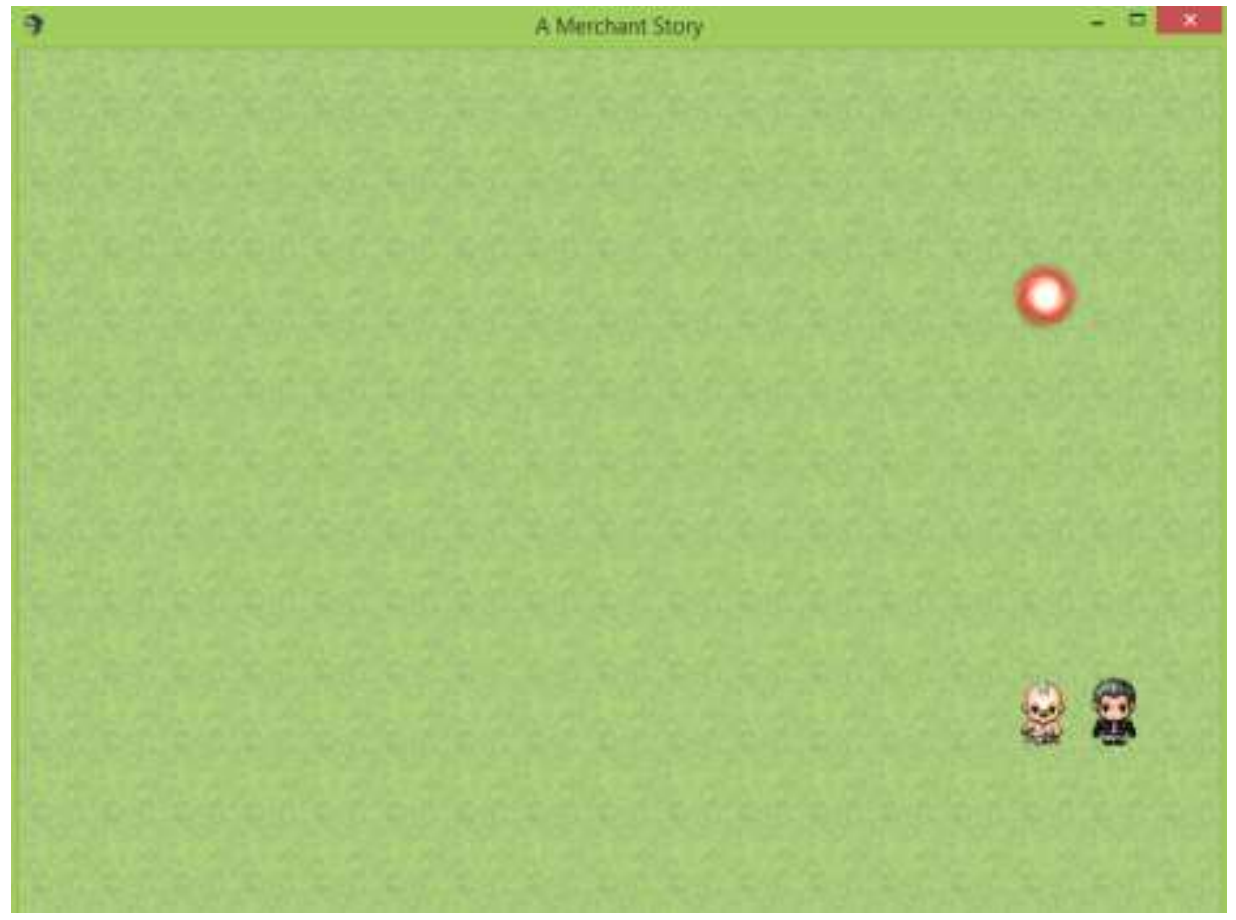

Gambar 10. Pengguna memperoleh teman/ relasi baru

\section{Kesimpulan}

Penelitian ini menggunakan model kognitif hirarki tugas dan tujuan (GOMS dan CCT) untuk merancang antarmuka dari game edukasi, dengan model aktivitas Appreciative Learning. Model GOMS dan CCT dapat digunakan dengan baik dalam game edukasi. Antarmuka dalam model ini dapat mengarahkan pengguna untuk dapat mengikuti rancangan aktivitas agar mencapai tujuan. Model ini mempermudah pengguna untuk berinteraksi, karena tujuan dan pilihan yang jelas dan bisa diprediksi. Aktivitas yang dikerjakan berkelanjutan dan dengan sudah adanya aturan yang jelas, membuat antarmuka aplikasi game edukasi ini menjadi lebih menarik dan menyenangkan untuk digunakan dalam proses pembelajaran.

Selain Model kognitif tersebut diatas, masih bisa diterapkan juga model lain yang dapat memprediksi waktu lama permainan, agar bisa tepat penggunaanya apabila diterapkan dalam proses pembelajaran dalam kelas. Perkembangan teknologi antarmuka terkini dapat pula diterapkan dalam game edukasi sehingga proses belajar lebih menantang dan menyenangkan.

\section{References}

[1] M. Simkova, "Using of Computer Games in Supporting Education," Procedia - Soc. Behav. Sci., vol. 141, pp. 1224-1227, 2014.

[2] V. Nagalingam and R. Ibrahim, "User Experience of Educational Games: A Review of the Elements," Procedia Comput. Sci., vol. 72, pp. 423-433, 2015.

[3] C. V. Zalka, "Adventures in the Classroom Creating Role-Playing Games Based on Traditional Stories for the High School Curriculum," East Tennessee State University, 2012.

[4] L. Caroux, K. Isbister, L. Le Bigot, and N. Vibert, "Player-video game interaction: A systematic review of current concepts," Comput. Human Behav., 2015.

[5] A. Dix, Human Computer Interaction. UK: Prentice- Hall International, 2003. 
[6] E. Y. Leng, W. A. Wan Zah, R. Mahmud, and B. Roselan, "Appreciative Learning Approach as a Pedagogical Strategy and Computer Game Development as a Technological Tool in Enhancing Students' Creativity," J. Res. Cent. Educ. Technol., vol. 7, no. 2, pp. 60-85, 2011

[7] B. Schmitz, M. Str, R. Klemke, and M. Specht, "Game Based Learning for Computer Science Education," pp. 81-86, 2011.

[8] E. T. Solovey, E. M. Peck, S. W. Hincks, R. J. K. Jacob, E. T. Solovey, and D. Afergan, "Designing Implicit Interfaces for Physiological Computing: Guidelines and Lessons Learned Using fNIRS," Tochi, vol. 21, no. 6, p. 35:1-35:26, 2015.

[9] F. Liarokapis, K. Debattista, A. Vourvopoulos, P. Petridis, and A. Ene, "Comparing interaction techniques for serious games through brain-computer interfaces: A user perception evaluation study," Entertain. Comput., 2014.

[10] K. Ryokai, F. Farzin, E. Kaltman, and G. Niemeyer, "Assessing multiple object tracking in young children using a game," Educ. Technol. Res. Dev., vol. 61, no. 2, 2013.

[11] D. Sonntag, "Kognit: Intelligent Cognitive Enhancement Technology by Cognitive Models and Mixed Reality for Dementia Patients," in AAAI 2015 Fall Symposium, 2015, vol. FS-15-02, pp. 47-53. 